\title{
Designing a Smart Mirror as a Laboratory Information Media Using Raspberry Pi
}

\author{
Denny Hardiyanto ${ }^{1}$, Galang Wicaksono ${ }^{2}$, Anggoro S Pramudyo ${ }^{3}$, Rian Fahrizal ${ }^{4}$, Romy Wiryadinata ${ }^{5}$
}

\begin{abstract}
Development of microprocessor technology provides new ideas for creating smart devices, one of which is in the field of smart home. Smart home is a concept of a home integrated with a smart system and supported by technology that enables all work to be more effective and efficient. Mirror is a household device that is beneficial to humans. In this paper, a research on smart mirrors is explained. A smart mirror is a mirror integrated with an intelligent system so that it can display multimedia data originating from the internet using Raspberry as a computing tool, PIR sensor as a tool to control monitors, and DC fans as a tool to control temperature system. In this paper, the mirror was able to display information about time, weather, academic calendar, lab work schedules, prayer schedules, and academic news. A PIR sensor has a good accuracy when the device is placed at $180 \mathrm{~cm}$ above the ground and the distance between mirror and humans when mirroring is $70 \mathrm{~cm}$. A DC fan was utilized to stabilize the system temperature in a range of 40 to $50^{\circ} \mathrm{C}$.
\end{abstract}

Keyword-Smart Mirror, Raspberry Pi, PIR Sensor, DC Fan, Smart Home.

\section{INTRODUCTION}

Microprocessor technology is growing faster, a System on Chip (SOC) becomes one of the evidences. An introduction of systems on chips (SOC), such as Raspberry Pi, has provided many new ideas for creating smart devices and nowadays one of the most popular projects using SOC is a development of smart home [1]. A smart home system is a computer-based system that will provide all the comfort, safety, security, and energy savings that take place automatically and it is programmed through a computer [2].

Mirrors have the potential to serve daily needs that have a reflective surface and have an interactive display. Therefore, it is possible if the mirror is combined with technology to become a smart mirror [3], [4]. Smart mirror has a display that looks and functions like a mirror, but has the ability to display multimedia data through the mirror glass as if it were a mirror screen [5].

Generally, smart mirro rs are made using two-way glass, monitors, frames for retaining glass and monitors, and web browsers with JavaScript to provide software and display [6]. In addition, it can also be equipped with a speech processing system [7], [8]. Smart mirror works like an application on a smartphone such as a widget or module that only has functions

${ }^{1}$ Dept. of Electrical Engineering, Faculty of Industrial Technology, IST AKPRIND Yogyakarta, Jln. Kalisahak No.28 Kompleks Balapan, Yogyakarta 55222 INDONESIA (tlp: 0274563029; e-mail: denny.hardiyanto@akprind.ac.id)

2,3,4,5 Dept of Electrical Engineering, Faculty of Engineering, Universitas Sultan Ageng Tirtayasa (e-mail: wiryadinata@untirta.ac.id) or commands [9]. Smart mirror enables its users to make customization and adjustments to provide personal services. To do this, the smart mirror needs to identify the user standing before it in order to make it able to access and display the user's personal information [5].

Researches on smart mirrors have also been done before, but they focused more on updating data and the use touch screen, so that it can only bring up a little information, namely time and notes [10]. Another research aimed to display information on the mirror was also done by adding voice recognition, so that it could facilitate an order, but it still lacked of information needs because it only displayed information about time, weather, and news feeds [7]. The research only focused on managing information through smartphone, making it difficult for users to update data because the provided data was only information available on the smartphone [11]. Research on smart mirrors to control homes has also been carried out. All information displayed on the screen was used to control the home, one of which was to open the doors and adjust the light. The weakness of that research is the absence of information to meet user needs.

From various previous research references in the field of smart mirrors, only a few of them present information for daily needs. Therefore, a smart mirror that is able to display news information, practicum schedules, academic agendas, prayer schedules, weather, and other multimedia information was designed. In addition to displaying information, this smart mirror research also added a PIR sensor as a monitor control and a DC fan that was used to control the system temperature to remain stable. It is expected that this device making can assist students or lecturers in complying with their information needs, one of which is academic information.

\section{METHODS}

Smart mirror is a device developed to display data in the form of information on the mirror. Fig. 1 shows that the smart mirror has two inputs, namely the PIR sensor and internet information (API, iCal, and Rss).

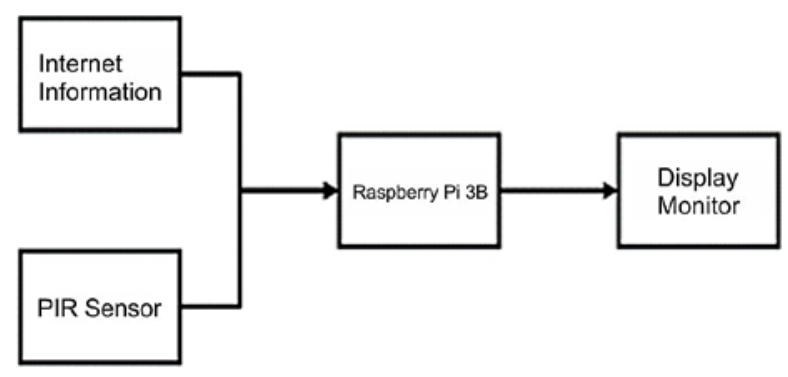

Fig. 1 Diagram block of a smart mirror.

PIR sensor served to send a signal to the Raspberry to change the monitor mode to energy saving mode if there was no one 


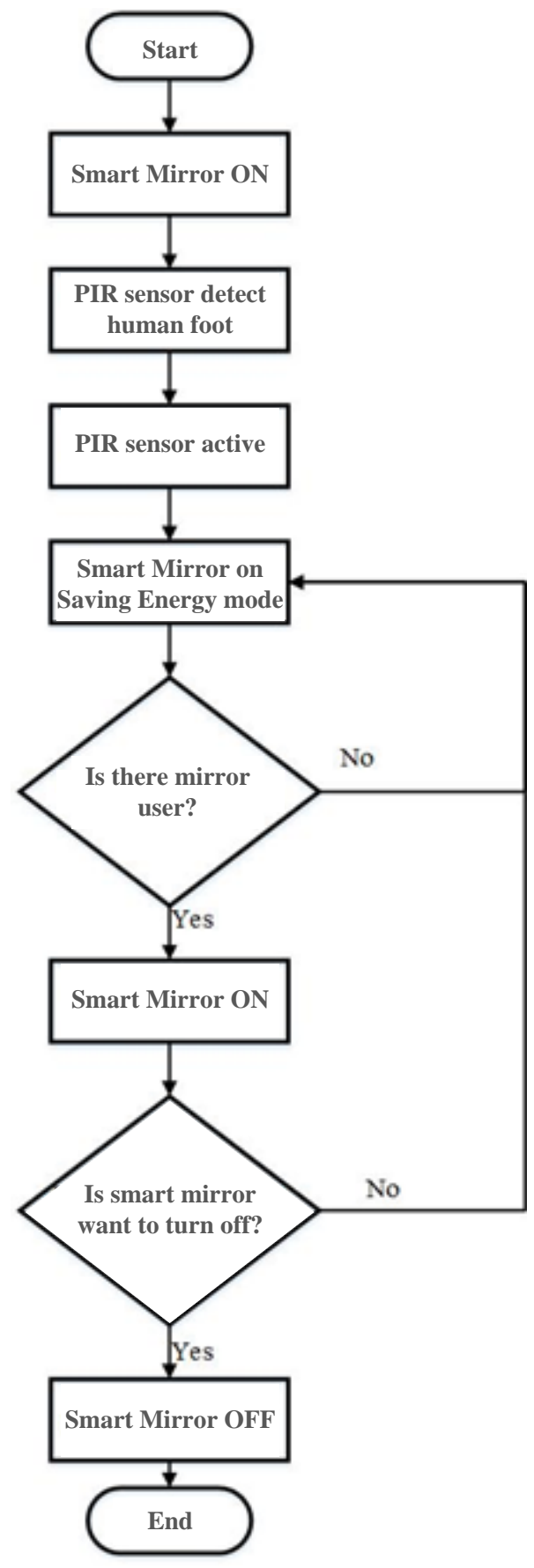

Fig. 2 Workflow of the smart mirror.

who mirrored. Internet information was used to synchronize modules with internet data so that information from the internet could appear on the screen and could be updated automatically.

Raspberry is a mini computer used to process information on a smart mirror. This information was generated by a program developed from a website that contained a collection of information. The information in the smart mirror was connected to the internet network, therefore the displayed data was actual.

Smart mirror required a mirror to be utilized to display information from the monitor. The utilized mirror was a one- way mirror. This mirror had the ability to transmit light from the monitor, so the mirror looks like a monitor.

Smart mirror ON was a state when the device started working. In this situation, the PIR sensor was not yet active and had to be activated by mirroring, namely by detecting the feet. When there was a user or someone who was looking at the mirror, the sensor would be active and it transmitted signals to Raspberry to change the monitor mode into energy savings mode. After a few seconds, monitor would turn off and it will turn on again when there was someone using the mirror. This process was repeated until the smart mirror was turned off. A flowchart of the smart mirror design is shown in Fig. 2.

PIR sensor works by transmitting signals to Raspberry to change the mode into energy savings mode. This mode commands the monitor to be inactive and change the Raspberry mode into sleep mode so that it keeps a stable temperature when the smart mirror is not being used. Fig. 3 shows a wiring diagram of the sensor.

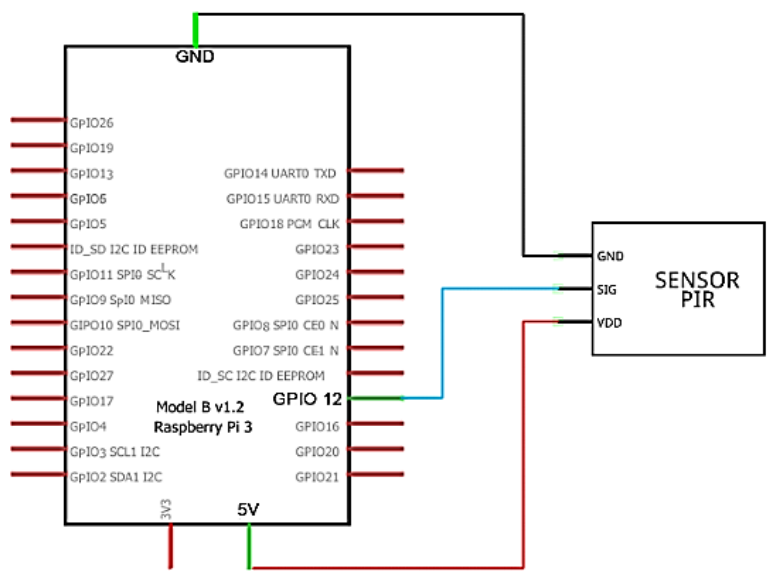

Fig. 3 PIR sensor wiring diagram.

In Fig. 3, the red cable is Vdd which is connected to pin 2 of the Raspberry (DC $5 \mathrm{~V}$ ). This pin serves to provide power to the sensor in order to work. The blue cable is the output that is connected to pin 12 of the Raspberry (GPIO 1), that serves to transmit input in a form of signals from PIR sensor to the Raspberry. The black cable is a ground connected to pin 9 of the Raspberry (Ground) and generally this pin is connected to the $0 \mathrm{~V}$ pin.

In this research, the information that would be displayed on the mirror was designed. Information that would be displayed on the mirror is information on time, weather, academic agendas, prayer time, compliment, campus information, and practicum schedules. This information utilized API, iCal, and Rss technology obtained from various websites to automatically synchronize data with modules.

Smart mirror works like smartphones, which require applications to carry out and conduct a task. However, in the smart mirror a widget or module instead of an application that works to do the task. Module is program running on a web side written using JavaScript and css, so that it resembles an application.

The utilized control system is Raspberry Pi Raspberry provides output to transistor that works as a switch to transmit 


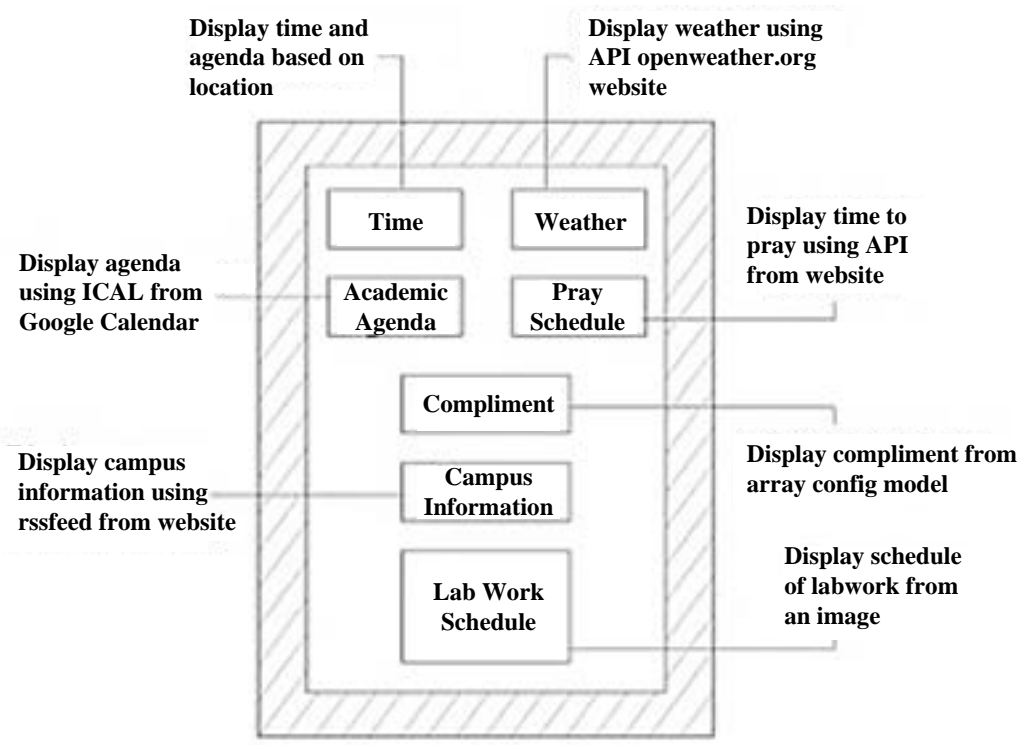

Fig. 4 Design of smart mirror information.

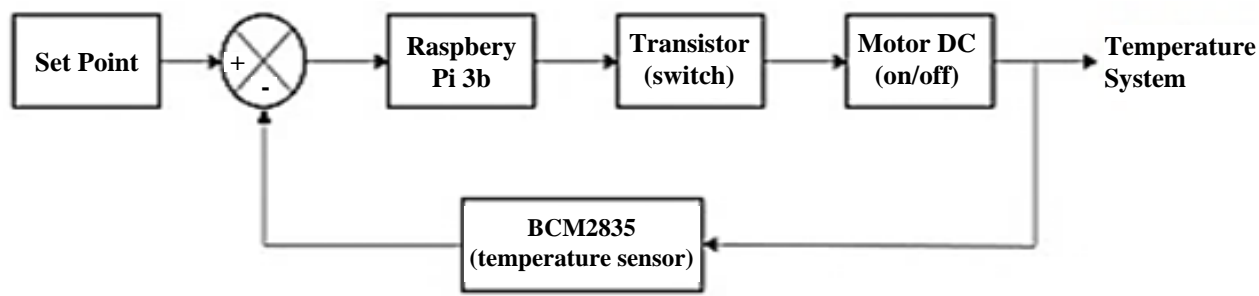

Fig. 5 Design of fan control.

current to the fan, so that the fan automatically rotates. The system temperature will be read by the BCM2835 sensor which then the sensor value will be compared with a set point value. The comparison between set point value and sensor value is called error value. This value will be the Raspberry input which later be manipulated, so the fan will turn on to control the system temperature. The design of information that will be displayed on the screen is shown in Fig. 4.

A fan control was made to keep the system temperature at the desired value by adjusting rotation speed of motor in DC fan based on maximum and minimum value of the system temperature. Fig. 5 shows a design of fan control. The fan was rotated by connecting pin 4 of Raspberry (DC 5 V) with positive red cable and connected negative black cable to an emitter transistor lead, then connected the collector transistor lead to the ground pin (black cable) and base transistor lead to pin 18 of Raspberry (red cable) The pi fan wiring diagram with Raspberry is shown in Fig. 6.

One-way mirror is an essential part in making a smart mirror. One-way mirror serves to pass the light from monitor to mirror that makes as if the mirror appears displaying a graphic. In thin tis paper, the one-way mirror was made with two materials, namely acrylic and silver tinted film. The frame was made using teak wood with a size of $50 \mathrm{~cm}$ x $40 \mathrm{~cm}$ x $7 \mathrm{~cm}$. This size was designed to a minimum so that all electronic devices could be in the frame and in the smart mirror. The front and back view design are shown in Fig. 7. This frame part is a place to put the one-way mirror and the monitor. This part will look transparent when exposed to light, so that all parts that have colour, except black, must be covered by black so that the light does not bounce, but only absorbed. The circle at the bottom is the place to put the PIR sensor. This sensor was put in the bottom so it is invisible to human eyes and it is able to read parts of the body, namely the legs. Diameter of the circle is $3 \mathrm{~cm}$.

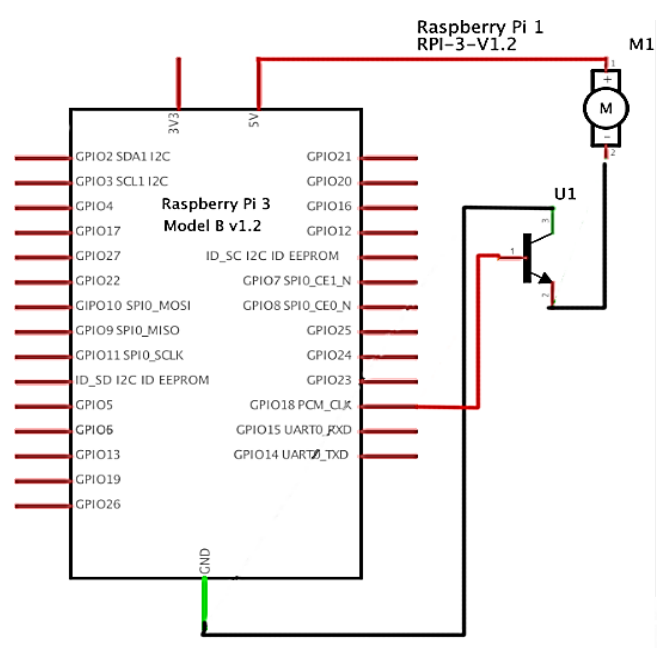

Fig. 6 Wiring diagram of DC fan control. 


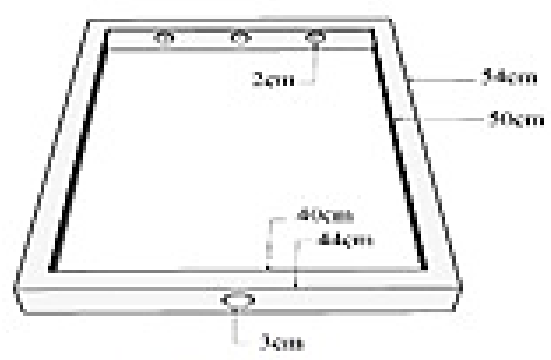

Front View

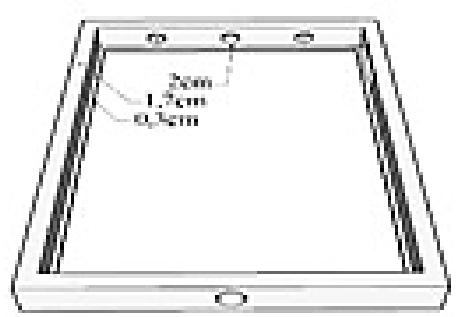

Back View

Fig. 7 Frame design of front and back sides.

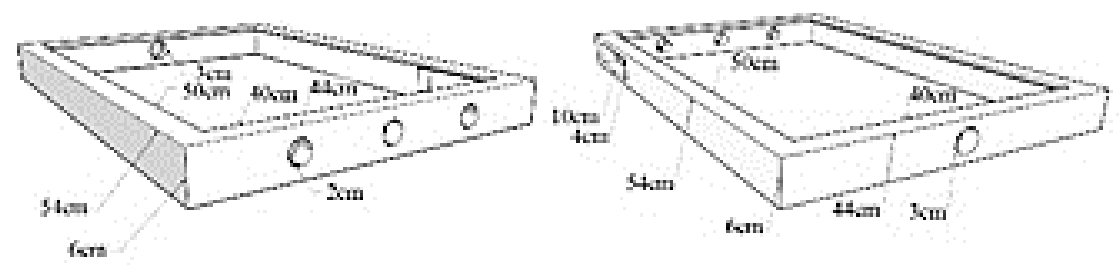

Fig. 8 Side frame design.

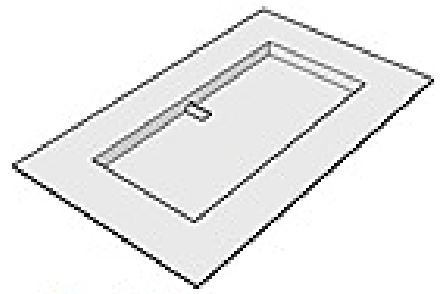

Inside Cover

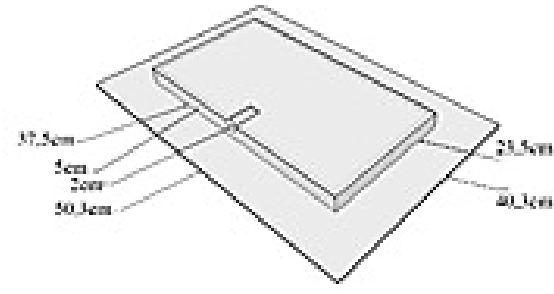

Outside Cover

Fig. 9 Smart mirror cover design.

The frame side, as shown in Fig. 8, is a place to put the Raspberry. In this part, a USB port on the Raspberry is shown outwards to facilitate a direct data update using USB flash.

Fig. 9 shows a cover part, consisting of two parts, the top and bottom parts. The top part has two covers that can be removed and be installed. This part is covered so that the monitor does not fall when the frame is mounted. The back side has no cover. It aims to enable monitor to forward the light to the one-way mirror.

\section{RESULTS AND DISCUSSION}

After conducting research to design a smart mirror that functions to display information on the mirror, the final result of the smart mirror design is shown by Fig. 10. In Fig. 10, the displayed modules are time, weather, academic calendar, news, prayer schedules, compliment and practicum schedules. Academic information was not successfully displayed because the official website of Universitas Sultan Agung Tirtayasa did not have rssfeed that was used to share information to different websites or platforms.

The final results of the smart mirror frame design made with teak wood was consisted of four main parts, namely the front page to put the one-way mirror, the back part to put the LED monitor, the bottom part to put the PIR sensor and the last it left part to put the Raspberry Pi 3B as shown in Fig. 11.
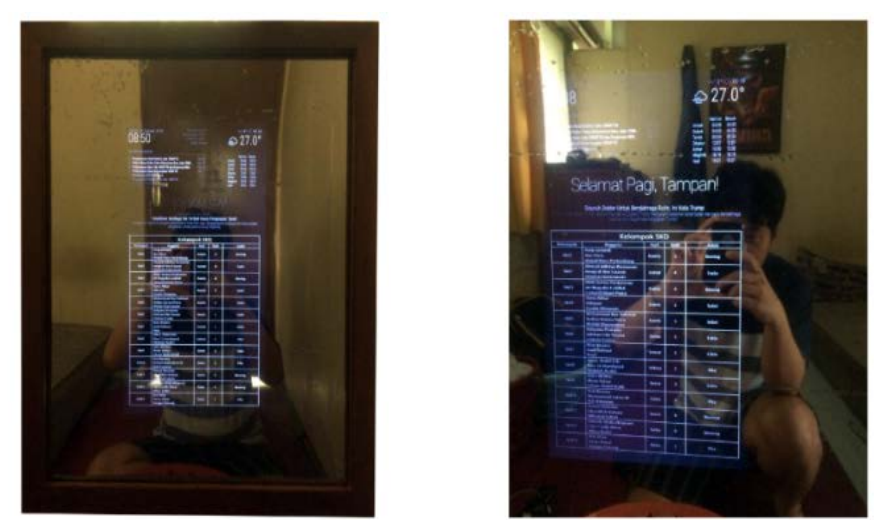

Fig. 10 Smart mirror.

A PIR sensor testing was carried out to determine the mirroring effectiveness by finding the right parameter value, namely height of the smart mirror, mirroring distance, equipment types, and the clothes worn by the person. The first test was carried out by changing the height of smart mirror on the wall, then mirroring from the farthest distance that was still possible to be read by PIR sensor so that the results of measuring the farthest distance from PIR sensor to the object were obtained. Test results of mirroring distance are presented in Table I. 


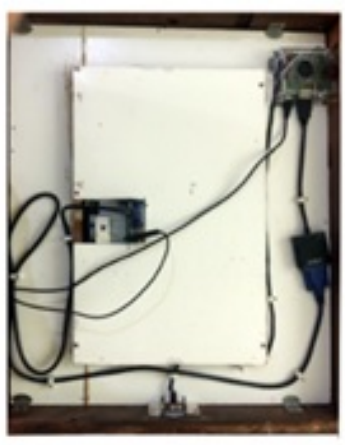

Back

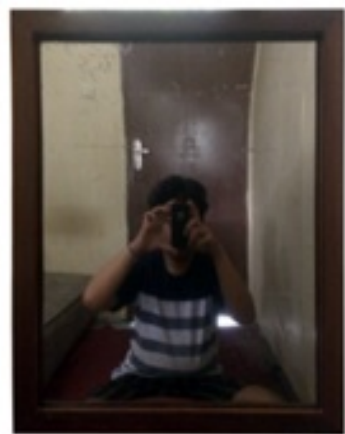

Front Side

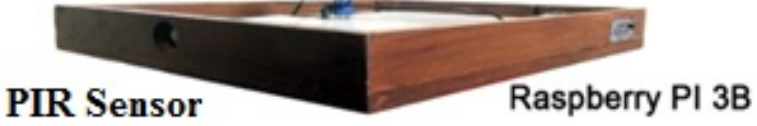

Fig. 11 Smart mirror frame.

TABLE I

TEST Results OF MiRRoring Distance

\begin{tabular}{|c|c|}
\hline Mirror Height (cm) & Average Distance (cm) \\
\hline 110 & 30.16 \\
\hline 120 & 37.56 \\
\hline 130 & 33.60 \\
\hline 140 & 38.88 \\
\hline 150 & 44.18 \\
\hline 160 & 53.76 \\
\hline 170 & 61.40 \\
\hline 180 & 68.04 \\
\hline 190 & 76.82 \\
\hline
\end{tabular}

From the test results in Table I, it can be seen that for each increase of $10 \mathrm{~cm}$ smart mirror on the wall, the obtained farthest distance will increase by as much as 7-8 cm. A PIR sensor object detection test aimed to test whether the equipment and the clothing worn affected the PIR sensor performance or not. Test was carried out by bringing the object worn closer to the sensor. If the object was brought to the sensor made the smart mirror turned on, it meant that the given logic was 1 , and vice versa, if the smart mirror still turned off when the object was brought closer, then the logic value was 0 . The results of PIR sensor object detection are shown in Table II.

TABLE II

Test Results of Detecting PIR Sensor OBJects

\begin{tabular}{|c|c|}
\hline Object & Response (s) \\
\hline Fabric Trousers & $>1$ \\
\hline Jeans & \pm 1 \\
\hline Socks & $<1$ \\
\hline Canvas Shoes & $>1$ \\
\hline Leather Shoes & \pm 1 \\
\hline
\end{tabular}

From the test results in Table II, it can be concluded that PIR sensor can still detect human body even though it is covered with everyday equipment and daily clothing. A PIR sensor sensitivity test aimed to determine the distance which still enabled the sensor to obtain a good sensitivity value, so that a reference to mirror on that distance was obtained. The PIR sensor sensitivity test results are presented in Table III.
TABLE III

PIR SENSOR SENSITIVITY TEST

\begin{tabular}{|c|c|}
\hline Mirroring Distance (cm) & Response (s) \\
\hline 30 & $<1$ \\
\hline 40 & \pm 1 \\
\hline 50 & \pm 1 \\
\hline 60 & $>1$ \\
\hline 70 & $>1$ \\
\hline 80 & $>1$ \\
\hline
\end{tabular}

From test results in Table III, it can be concluded that the closer the human body is to the sensor, the better response will be obtained. The response value is given based on the time delay given by the PIR sensor to turn on the screen.

System load test was carried out to determine the level of load usage used to run the smart mirror. In the first experiment, a system load test per module was carried out, the data shown were the use of RAM and CPU, also system temperature. Test results are shown in Table IV.

TABLE IV

LOAD TEST PER MODULE

\begin{tabular}{|l|c|c|c|}
\hline \multicolumn{1}{|c|}{ Module } & RAM (\%) & CPU & $\begin{array}{c}\text { CPU } \\
\text { Temperature }\left({ }^{\mathbf{}} \mathbf{C}\right)\end{array}$ \\
\hline Time & 55 & 0.58 & 44 \\
\hline Academic Calendar & 56 & 0.47 & 47.2 \\
\hline Compliments & 56 & 0.86 & 47.8 \\
\hline Weather & 56 & 0.66 & 47.2 \\
\hline News & 55 & 1.46 & 44 \\
\hline Practicum Schedule & 57 & 1.02 & 47.9 \\
\hline Prayer Schedule & 55 & 0.74 & 45.1 \\
\hline
\end{tabular}

From the test results in Table IV, it can be concluded that the more moving animation, the larger the module size that is displayed, and the more frequently the information is updated, the greater the system load used by the module. A smart mirror system load was also tested for 24 hours with the aim of testing the system durability. Test was carried out by taking data of CPU, RAM and system temperature every hour. Results of CPU temperature test are shown in a graphical form in Fig. 12.

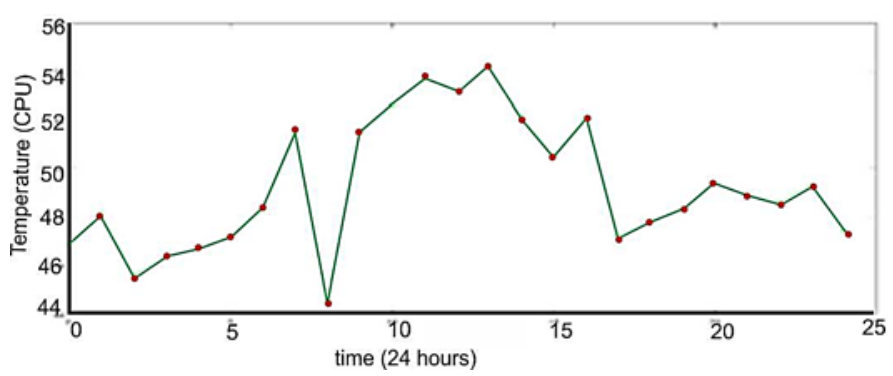

Fig. 12 CPU temperature graph.

From the tests that have been conducted, it can be concluded that the smart mirror can last turned on for 24 hours with a system temperature between $40-50{ }^{\circ} \mathrm{C}$. The system load value continues to change because each module update data at different times, causing the system load to be unstable. The system load testing results in graphical form are shown in Fig. 13.

RAM values continue to increase due to smart mirror services that continue to run in the system background. RAM 
values continue to increase due to smart mirror services that continue to run in the system background. The system load test results are shown in a graph in the Fig. 14.

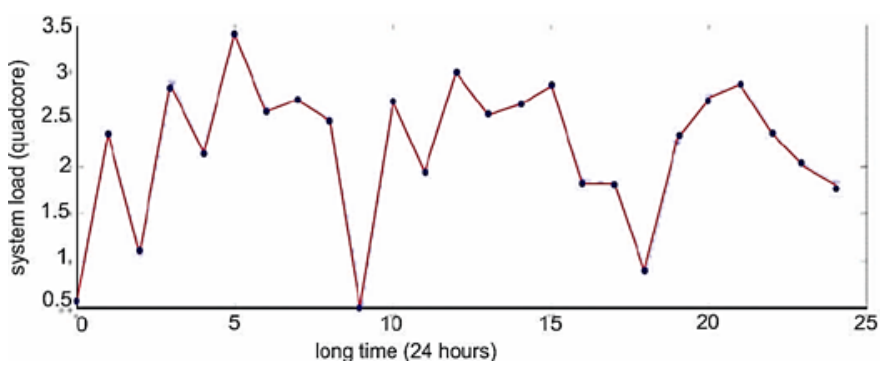

Fig. 13 Graph of CPU system load.

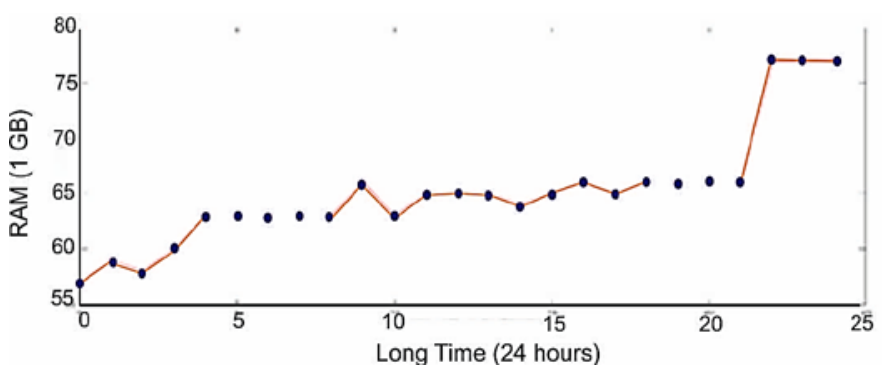

Fig. 14 Graph of RAM load.

From this test, it is notable that to turn on the smart mirror for more than 24 hours there are several things to be considered, namely the smart mirror must be placed in a place with a temperature bellow $30^{\circ} \mathrm{C}$ so that the CPU temperature remains stable. If the RAM has reached the limit, the performance of the device will get worse, therefore the smart mirror must be restarted so that the system load returns to normal and can reperform the process properly.

\section{CONCLUSION}

After analysing the tests that have been carried out, there are several conclusions, namely information that has been successfully created and successfully displayed on the smart mirror are time information, academic calendar, weather at Cilegon area, news, practicum schedules, prayer times, and compliments. Effective mirroring can be carried out by placing a smart mirror at a height of $180 \mathrm{~cm}$ with a mirroring distance of $70 \mathrm{~cm}$. From the 24-hour load testing, the average RAM value was $67 \%$, CPU load was 1.19 , and the system temperature was $48{ }^{\circ} \mathrm{C}$.

Further researches are expected to improve and develop this research. For example, there can be an experiment to replace the mirror with an original one-way mirror, because in this test, by combining acrylic and window film, the results obtained in black can still be seen by the eye, so that the monitor shape is visible when looking in the mirror. In addition, a large screen or display can be used, a minimum of 22 inches, because the use of sizes below 22 inch causes users to have to look closely to read information on the smart mirror.

\section{ACKNOWLEDGEMENTS}

Acknowledgments were expressed to the research team for completing this research. Gratitude also expressed to all lecturers of the Department of Electrical Engineering, Faculty of Engineering, Universitas Sultan Ageng Tirtayasa, and lecturers majoring in Electrical Engineering, Faculty of Industrial Technology, IST AKPRIND Yogyakarta.

\section{REFERENCES}

[1] D. Gold, D. Sollinger, and Indratmo, "Smartreflect: A Modular Smart Mirror Application Platform," 7th Annual Information Technology, Electronics and Mobile Communication Conference (IEMCON), 2016, pp. 1-7.

[2] Y. Kashimoto, M. Fujiwara, M. Fujimoto, H. Suwa, Y. Arakawa, and K Yasumoto, “ALPAS: Analog-PIR-Sensor-Based Activity Recognition System in Smarthome," 31st International Conference on Advanced Information Networking and Applications (AINA), 2017, pp. 880-885.

[3] J.-R. Ding, C.-L. Huang, J.-K. Lin, J.-F. Yang, and C.-H. Wu, "Interactive Multimedia Mirror System Design,” IEEE Trans. Consum. Electron., Vol. 54, No. 3, pp. 972-980, 2008.

[4] H. Sukeda, Y. Horry, Y. Maruyama, and T. Hoshino, "InformationAccessing Furniture to Make Our Everyday Lives More Comfortable,” IEEE Trans. Consum. Electron., Vol. 52, No. 1, pp. 173-178, 2006.

[5] M.A. Hossain, P.K. Atrey, and A. El Saddik, "Smart Mirror for Ambient Home Environment," IET International Conference on Intelligent Environments, 2007, pp. 589-596.

[6] M. Ghazal, T. Al Hadithy, Y. Al Khalil, M. Akmal, and H. Hajjdiab, “A Mobile-Programmable Smart Mirror for Ambient IoT Environments,” 5th International Conference on Future Internet of Things and Cloud Workshops (FiCloudW), 2017, pp. 240-245.

[7] V. Khanna, Y. Vardhan, D. Nair, P Pannu, "Design and Development of A Smart Mirror Using Raspberry Pi," International Journal of Electrical, Electronics and Data Communication. Vol. 5, No. 1, pp. 63-65, 2017.

[8] G. KarpagaRajesh, L.A. Jasmine, S. Anusuya, A. Apshana, S. Asweni, R.H. Nambi, "Voice Controlled Raspberry Pi Based Smart Mirror," International Research Journal of Engineering and Technology, Vol. 6, No. 5, pp. 1980-1984, 2019.

[9] S. Athira, F. Francis, R. Raphel, N.S. Sachin, S. Porinchu, and S. Francis, "Smart Mirror: A Novel Framework for Interactive Display," International Conference on Circuit, Power and Computing Technologies (ICCPCT), 2016, pp. 1-6.

[10] M.M. Yusri, S. Kasim, R. Hassan, Z. Abdullah, H. Ruslai, K. Jahidin, and M.S. Arshad, "Smart Mirror for Smart Life," 6th ICT International Student Project Conference (ICT-ISPC), 2017, pp. 1-5.

[11] Y. Sun, L. Geng, and K. Dan, "Design of Smart Mirror Based on Raspberry Pi," International Conference on Intelligent Transportation, Big Data \& Smart City (ICITBS), 2018, pp. 77-80. 